asHOKa

UNIVERSITY

Ashoka University Economics

Discussion Paper 60

\title{
What's in a Name? Reputation and Monitoring in the Audit Market
}

\section{May 2021}

Somdutta Basu, Morgan Stanley

Suraj Shekhar, Ashoka University 


\title{
What's in a Name? Reputation and Monitoring in the Audit
}

\author{
Market* \\ The latest draft of this paper can be found on surajshekhar.com \\ Somdutta Basu $^{\dagger 1}$ and Suraj Shekhar ${ }^{\ddagger 2}$ \\ ${ }^{1}$ Morgan Stanley \\ ${ }^{2}$ Ashoka University
}

May 2019

\begin{abstract}
We study incentives under different information regimes by analyzing a rule change in the audit industry in the USA. Since February 2017, the name of the engagement partner has to be disclosed for all audit reports issued in the USA. We show that this quest for transparency has its pitfalls despite the increase in the level of information for investors. While the higher reputation building incentives can improve audit quality, an unintended consequence of the rule is that audit partners have a lower incentive to monitor other partners when names are disclosed. We find conditions under which the latter effect dominates the former. (JEL -
\end{abstract} L14, L51, M42)

Keywords - Audit, Disclosure, Collective Reputation, Engagement partner, Monitoring

\footnotetext{
* Most of the research in this paper was conducted while Somdutta Basu was a fellow at the Public Company Accounting Oversight Board (PCAOB) and Suraj Shekhar was a graduate student at the Pennsylvania State University. The PCAOB, as a matter of policy, disclaims responsibility for any private publication or statement by any of its Economic Research Fellows and employees. The views expressed in this paper are the views of the authors and do not necessarily reflect the views of the Board, individual Board members, the staff of the PCAOB, or that of Morgan Stanley. This research did not receive any specific grant from funding agencies in the public, commercial, or not-for-profit sectors. Declarations of interest: none. Data sharing is not applicable to this article as no new data were created or analyzed in this study. We would like to thank Kalyan Chatterjee, Jeremy Bertomeu, Vijay Krishna, Luigi Zingales, Christian Leuz, Patricia Ledesma, Michael Gurbutt, Marcelo Pinheiro, Joon-Suk Lee, Morris Mitler, PCAOB staff, seminar participants at the 2016 Junior Accounting Theory Conference at NYU Stern and Baruch College, seminar participants at the Pennsylvania State University, seminar participants at the University of Cape Town, seminar participants at Stellenbosch University, seminar participants at PCAOB, Kathryn Spier and three anonymous referees for helpful comments on earlier versions of this work.

${ }^{\dagger} 1585$ Broadway, New York City, New York, USA. Email: somdutta.basu@gmail.com

¥Corresponding author. 343/2, AC-02 building, Ashoka University, Sonipat, Haryana-131029, India. Email: suraj.shekhar@ashoka.edu.in
} 


\section{Introduction}

Before February 2017, audit reports issued in the USA did not reveal the name of the lead partner at the audit firm who conducted the audit. In December 2015, the Public Company Accounting Oversight Board (PCAOB) approved a new rule which mandates that the lead partner's name be disclosed to capital market participants. ${ }^{1}$ This rule was approved by the Securities and Exchange Commission (SEC) in May 2016, and has come into effect in February $2017 .^{2}$ One would expect that since the rule increases the level of information available to market participants, it will lead to better outcomes (or at least, no worse than before) in terms of audit quality. However, this line of reasoning ignores how this transparency increasing rule changes the incentives of the players (auditors) in the game.

Our paper contributes to the literature by demonstrating how reputation and monitoring incentives within a firm can be affected by changes in the information structure of the environment. In particular, the rule change described above allows us to compare two information regimes: a collective reputation (when partner names are not disclosed) set up where partners within an audit firm share a reputation, and an environment where players have the possibility of developing individual reputations (when partner names are disclosed) while still sharing in the revenue generated by other players. We identify conditions under which the higher information regime (where names are disclosed) has lower audit quality. Furthermore, we identify which type of clients are more likely to receive lower quality audit reports.

We study a two period model where we have an audit firm which has two partners, one client who wishes to be audited, and an investor who may invest in the client based on the audit report. The client's finances can be in good or bad shape in any period. In every period, one of the two audit partners audits the client and the other works on a different engagement. The partner auditing the client gets a noisy signal about the client's finances in that period, which he is supposed to report to the investor. The client firm always prefers a favorable audit report and can put pressure on the audit partner to issue a good report. Keeping this possibility in mind, the audit firm has the audit partners monitor each other via partner rotation wherein the partner who audits the client changes in period two with positive probability. A new partner can detect if the previous partner's audit report matches the audit signal that partner received. If the new partner truthfully reports a discrepancy between the report and the signal, the first period partner is fired (observed by all players). An audit partner can be one of two types. One type is strategic and succumbs ${ }^{3}$ to high enough pressure by the client, while the other type is non-strategic and always issues the correct report. The audit fee is directly proportional to the reputation (probability of being non-strategic) of the audit partner, and each audit partner gets a share of profits from all engagements of the

\footnotetext{
${ }^{1}$ Instead of requiring that the partner's name be revealed in the audit report itself, the rule mandates that the partner should be identified through form AP on the PCAOB website. This is for legal purposes. From an information disclosure perspective, it serves the same purpose as disclosing the name in the audit report. The information will be available in a searchable database on the Board's web site.

${ }^{2}$ SEC (2016).

${ }^{3}$ Issue a favorable report even if the signal is bad.
} 
audit firm. The true state of the client's finances is revealed at the end of each period (after the audit partner has issued a report, and after the investor has made his investment decision). In this environment, we study how disclosing the name of audit partners can affect the reputation building incentive and the monitoring incentive of the partners. Name disclosure changes the information environment in the following way. When partner names are disclosed, the investor knows exactly which partner works on the client's audit in each period (disclosure regime), whereas when names are not revealed (non-disclosure regime), the investor is uncertain about which audit partner worked on the client's audit report in any period.

We show that the disclosure of partner names impacts the monitoring and reputation building incentives in opposite ways. The disclosure of partner names allows for individual reputations and makes a partner's reputation (and therefore future payoffs) more sensitive to his actions. This generates incentives for the partner to improve the quality of audit reports (not succumb to client pressure) to build reputation. ${ }^{4}$ Thus, this reputation effect pushes audit quality up. This was one of the primary reasons for introducing the new rule.

The second effect of the new rule however, affects audit quality negatively. We show that an unintended consequence $^{5}$ of this regime change is that the incentives to monitor a fellow partner are lower under the disclosure regime, and this can lead to lower audit quality. This works in the following way. Suppose the first period partner succumbed to the client's pressure and issued an incorrect audit report. In the second period, if partners are rotated, the new partner realizes that his predecessor's report was influenced. What are his incentives to report the first period partner in the two regimes? If he does not report the partner, there will be no firing. In the non-disclosure regime, the investor does not observe if the partner has been rotated. Thus, when the investor observes that the audit report did not match the client's financial state but there was no firing, the investor believes that this could happen because the audit partner got the incorrect signal by mistake and was therefore not reported ${ }^{6}$, or it could be because the audit partner in period one succumbed to the client's pressure, and was not fired because there was no partner rotation. ${ }^{7}$ The latter possibility reduces the reputation of the engagement partner in period two, and the new engagement partner can restore his reputation by reporting the first period partner. This works because reporting the first period partner will lead to the investor observing a firing, which makes the investor (correctly) believe that the audit partner must be a new one (because a partner would never report on himself). On the other hand, in the disclosure regime, the investor knows exactly which auditor conducts the audit. Thus, when the partners are rotated after an incorrect audit opinion was issued, the second period engagement partner comes in with an untarnished reputation. In other words, the incentive to monitor a fellow partner reduces with identification because actions taken by one partner no longer affects the

\footnotetext{
${ }^{4}$ Also see Hwang and Li (2018) for how increased reputational incentives can influence an analyst's decision. Furthermore, it should be noted that reputation concerns don't always improve outcomes (Corona and Randhawa (2010))

${ }^{5} \mathrm{We}$ call it an unintended consequence because we have seen no discussion of this effect in any paper or report.

${ }^{6}$ In this case, the partner did not issue a report different from his signal due to client pressure, the audit signal received by the partner was itself incorrect. This can happen because the audit signal received is a noisy one.

${ }^{7}$ A partner would never report on himself in any equilibrium.
} 
reputation of other partners (since reputation is not collectively shared with others under partner identification). Thus, this monitoring effect pushes audit quality down by reducing the threat of monitoring. John et al. (2017) study data from the UK (where the disclosure rule was implemented in 2009) and find supportive evidence for such a monitoring effect.

We find conditions under which this transparency inducing rule change can actually lead to lower quality audits i.e. the monitoring effect dominates the reputation effect. An interesting point we bring out is that when the client has the willingness (determined endogenously) to put a lot of pressure on the auditor to issue favorable reports, or can put very little pressure, then the disclosure of partner names is not worse than not disclosing them. It's only in the intermediate range that the disclosure regime performs worse than the non-disclosure regime. The intuition for this result is that when the client is too big, it can put a lot of pressure on the audit partner so that the audit report will be influenced in either regime. This is because they have too much to lose if they do not get a favorable audit report. On the other hand, when the client is too small, the incentives to report a fellow partner becomes too low even in the non-disclosure regime because the reputation gain from reporting is low. ${ }^{8}$ The empirical implication here is that it is the audit of an intermediate sized client which is likely to be negatively affected by this rule change. We propose several solutions to the monitoring problem including one where increased audit fee boosts reputation incentives to compensate for the lower monitoring incentives. This could be one of the explanations of the empirical findings of Carcello and $\mathrm{Li}$ (2013) where the authors report the joint occurrence of higher quality of audits and higher audit fees after audit partners were mandated to sign audit reports issued in the UK.

We have seen no papers or firm statements/concern-letters which talk about the monitoring issue we highlight. The reputation effect we highlight was known, and therefore it is possible that the manager of an audit firm reduces compensation incentives after the regime change because she believes that the increased reputation incentives would make the audit partner produce higher audit quality reports anyway. We show that such a move would be misguided and would exacerbate the monitoring issue we highlight even more. It is important to understand all the channels via which the disclosure rule can impact incentives to produce high quality audit reports, especially because this could affect empirical work as well. ${ }^{9}$ Finally, to the best of our knowledge this paper is the first to model the three relational aspects unique to the audit market (the leadership of the accounting firm to audit partner relationship via internal sanctions/firing, the partner-partner relationship via monitoring, and the partner's interaction with the client via client pressure) to explore the consequences of disclosing partner names. Although our model is streamlined to fit the audit context, our analysis speaks to the broader issue of incentives

\footnotetext{
${ }^{8}$ This is because both the strategic and non strategic type partners play a similar strategy when the pressure from the client is low. This causes the change in reputation after any history to be very low.

${ }^{9}$ For example, if the channel we highlight is not well known in the literature then empirical work on the impact of the rule change may (erroneously) completely attribute any compensation contract change following the implementation of the rule to other factors. One such factor could be the following. It has been argued that the disclosure of audit partner names may induce them to exert more diligence to avoid any perceived increase in legal liability.
} 
under collective reputation versus those under individual reputation models of partnerships. ${ }^{10}$

The remainder of the paper is organized as follows. The next section describes some of the related literature. Section 3 gives the context in which the new rule was imagined and implemented, and section 4 presents the formal model with partner rotation. Section 5 presents the analysis of equilibria in our benchmark model where the cost of reporting is positive. We relax this assumption and contrast our results to the zero cost of reporting case in the internet appendix. Section 6 discusses potential solutions to the monitoring problem, and section 7 discusses some of our modeling choices. Section 8 presents the summary and possible extensions of the model. The internet appendix is available on the web page http://surajshekhar.com/.

\section{Literature}

In this section, we describe the related literature. While this paper analyzes the change in incentives of partners and the impact on audit quality of the partner identification rule, at its heart this paper explores the more general issue of monitoring in collective reputation environments versus individual reputation environments. Thus, this paper is related to at least two strands of literature: first, the work on analyzing the impact of such laws in other countries (like Carcello and $\mathrm{Li}$ (2013)) and second, the literature on collective reputation and monitoring. Additionally, our paper shares some common themes with other papers who look at incentives in the audit market like Lee and Levine (2016). Finally, the central idea in the paper is related to Holmstrom and Milgrom (1991) paper on incentives in multitasking. We describe some of these papers next and highlight the important distinctions from our paper.

Empirical evidence on whether partner identification can lead to higher audit quality is mixed. Blay et al. (2014) find no evidence of improved audit quality following the implementation of the partner identification rule in the Netherlands. Carcello and Li (2013), on the other hand, document an increase in audit fees as well as an improvement in audit quality in the United Kingdom after this law was approved. The implications of our theory are consistent with the findings of Carcello and $\mathrm{Li} \mathrm{(2013).} \mathrm{We} \mathrm{show} \mathrm{that} \mathrm{a} \mathrm{sufficient} \mathrm{increase} \mathrm{in} \mathrm{audit} \mathrm{fee} \mathrm{can}$ raise reputation building incentives enough to compensate for the lack of monitoring incentives, thereby leading to an increase in audit quality.

The paper closest to our paper is Lee and Levine (2016). The authors look at individual partner incentives and the partnership's choice of internal quality control. They show that identifying the individual partner increases the individual partner's incentives by increasing accountability. However, they point out that partner identification decreases the partnership's incentive for choosing high cost-high value internal monitoring to motivate partners to exert high effort. As a result, the partnership's choice of internal quality control could be lower

\footnotetext{
${ }^{10}$ Another market to which the ideas of this paper can be directly applied is the credit rating market.
} 
in the partner identification setting which could lead to lower quality audits. Our paper differs from Lee and Levine (2016) in several significant ways. One, Lee and Levine (2016) allow the audit firm leadership to commit to monitoring level. In contrast, in our paper, monitoring is endogenous. Two, in Lee and Levine (2016), the quality of the audit depends upon the effort choice of the partner when the partner knows the cost of effort. In our paper, the partner's problem is whether or not to reveal his true signals in the face of an external cost which is endogenously determined in the model. ${ }^{11}$

In the audit theory literature, there are papers which illustrate how reputation building incentives can affect audit quality (Datar and Alles (1999), Corona and Randhawa (2010), Basu and Ray (2016)), and others which do the same for monitoring. However, we have not seen any paper which tackles these two incentives in the same model and highlights the tension between them, especially when the information environment changes. Beyer and Sridhar (2006) show that audit quality might actually go down as the audit oversight mechanism strengthens. Apart from the fact that they don't study reputation building incentives, the monitoring in this paper differs from that in ours because the monitoring technology is exogenously given in Beyer and Sridhar (2006) whereas monitoring is endogenously chosen in our paper. Furthermore, the benefit from misreporting is exogenously given in Beyer and Sridhar (2006) while it is endogenously determined in our model.

Obviously, our paper is also related to the long literature on reputation in repeated games starting from Kreps et al. (1982). Though earlier papers were concerned largely with individual reputation, since Tirole (1996) paper on collective reputation, we have seen substantial growth in papers dealing with collective reputation. Most theoretical research on collective reputation since however, has focused on the overlapping generations model of collective reputation (Bar-Isaac (2007), Chen et al. (2013)). Bar-Isaac (2007) argues that agents expend effort for individual reputation when young (since their prior reputation is low) and work for collective reputation (the reputation of the firm) when they are old. This paper sidesteps adverse selection issues and concentrates on moral hazard while in our model, we set aside issues of moral hazard and focus on reputation and monitoring in the presence of adverse selection. More recent papers like Neeman et al. (2068) also speak about the potential benefits of collective reputation. ${ }^{12}$ They study a model of collective reputation and use it to analyze the benefit of collective brands. ${ }^{13}$ They show that collective brands may induce stronger incentives to invest in quality than individual brands. However, unlike our paper, they do not look at the incentives to monitor and how it differs in a collective reputation environment and an individual reputation environment.

Chen et al. (2013) discuss a case where individuals may do worse on their own as compared to when they are part of a firm. Thus, it is possible to think of this as an analysis which highlights some differences between a collective reputation regime and an individual reputation regime. The authors show that if individual incentives

\footnotetext{
${ }^{11}$ Cost imposed by the issuer manager.

${ }^{12}$ Also see Fishman et al. (2014).

${ }^{13}$ For example, cares from Germany have a high reputation. So all German car makers share a collective reputation.
} 
to signal ability by taking actions which may not be optimal for the clients ${ }^{14}$ are very strong, then individuals may prefer to work at a firm where there their reputation building incentives will be known to be controlled by internal monitoring. In our paper, we consider the situation where partners are already working at a firm and we show how monitoring and reputation building incentives change when a partner identification rule changes the environment from a collective reputation regime to an individual reputation regime. Thus, the way profits within the firm are shared makes a big difference to our analysis (payoffs could be correlated across engagements). Moreover, in Chen et al. (2013), the monitoring capability of the owner of the firm is exogenously given, while it is endogenously chosen in our paper.

Holmstrom and Milgrom (1991) describes a seminal model of multitasking with a brilliant insight - when an agent has to perform multiple tasks and the incentive to perform one task improves, this task gets more attention/effort to the detriment of the other task. This idea is key to our results as well. Disclosure of partner name realigns the incentives of the audit partner by making reputation building via good quality audit reports more lucrative, while at the same time making monitoring less profitable. Our main distinction from Holmstrom and Milgrom (1991) is in pointing out how the disclosure of partner names can lead to a realignment of the two incentives. We show that disclosure of the audit partner's name makes the first period partner's reputation more sensitive to his own actions, whereas before (in the non-disclosure regime) any credit (from a correct audit report) or discredit (from an incorrect audit report) was shared amongst all partners. On the monitoring side, in the non disclosure regime, a partner who is rotated in to conduct the audit reports the other partner to improve his own reputation (and therefore payoff), whereas when names are disclosed, one partner's reputation is left untarnished by the actions of another.

\section{Context}

Before we describe our analysis and results, a bit of context is in order (more details and context is available in the internet appendix. ${ }^{15}$ ) An external auditor scrutinizes the financial statements of a legal entity or organization in accordance with specific laws or rules. This auditor is independent of the entity being audited. For example, Deloitte could be the audit firm auditing the financial statements of Coca-Cola. Users of the entity's financial information, such as investors, government agencies and the general public, rely on the external auditor to present an unbiased and independent audit report. Audit firms usually operate as partnerships and audit partners are responsible for managing the audit department and engaging in client audits. Unlike other jurisdictions such as several European Union (EU) countries and Australia, in the USA, the name of the lead audit partner was not disclosed to investors and other users of financial statements of publicly traded companies. This was problematic

\footnotetext{
${ }^{14}$ Think of investment bankers signalling their ability by coming up with complex derivatives which may not necessarily serve best the interests of their client. Also, see Ely and Välimäki (2003).

${ }^{15}$ Available on http://surajshekhar.com/
} 
for the following reasons. The Public Company Accounting Oversight Board's oversight activities reveal that audit quality varies across engagements within the big accounting firms (PCAOB (2013)). ${ }^{16}$ Researchers also argue that differences across individual partners may influence audit quality (DeFond and Francis (2005)). Consequently, compared to the identity of the audit partner, the identity of the accounting firm may constitute a less informative signal of audit quality for individual engagements. ${ }^{17}$ Furthermore, revealing partner names increases transparency. If an audit partner's name is revealed in the audit report, it could generate stronger incentives for the partner to build or protect his reputation via high quality audit reports. ${ }^{18}$

\section{Model}

In this section, we present the model in a simple two period set up where all agents are risk neutral. There is an audit firm with three partners: one managing partner (who acts as the leadership of the audit firm) and two engagement partners who can work on projects/auditing jobs. There is an issuer (client) who wishes to be audited, and every period there is an investor for whom the issuer's firm is an investment prospect. In our model, the managing partner of the audit firm and the investor are passive (behavioral) players. ${ }^{19}$ This simplification allows us to focus on the reputation and monitoring incentives faced by the engagement partners in the face of pressure from the issuer to issue favorable reports. The partners maximize the discounted sum of payoffs where the discount factor is denoted by $\delta$. The issuer is myopic and he maximizes only current period payoff. ${ }^{20}$ Note that our model considers the interaction between a client and one audit firm only. We do not study an environment in which there are other audit firms. We argue in section 7 that this simplification does not affect our qualitative results.

In each period the issuer's cash flow for that period is picked by nature and it takes one of two values: $G$ (good) and $B$ (bad) with probability $p$ and $1-p$ respectively. These probabilities are common knowledge. The investor wants to invest in the issuer only if the state is $G$. At the end of each period, the true cash flow of that

\footnotetext{
${ }^{16}$ Knechel et al. (2015) provide evidence that reporting 'style' varies systematically across individual auditors and persists over time. They argue that such differences could be due to systematic differences in risk tolerance or other idiosyncratic attributes of the partner which can affect decisions made during the course of the audit.

${ }^{17}$ To investigate if capital market participants (like investors) indeed value the information contained in the identity of individual audit partners beyond the information provided by the identity of the audit firm, Aobdia et al. (2015) use data from Taiwan and document positive association between the partner's quality and the client firm's earnings response coefficient. They also report positive market reaction when a firm replaces a lower quality partner with a higher quality one and they find evidence that firms audited by higher quality partners experience smaller Initial Public Offering (IPO) underpricing which allows them to obtain better debt contract terms. Overall, their results suggest that capital market participants place (and should place) a positive value on information which reveals the identity of the audit partner to them. Liu (2017) looks at UK data and finds that requiring the engagement partner's name to be disclosed led to a reduction in the analysts' forecast errors.

${ }^{18}$ The argument of transparency also works if there are legal consequences for the auditor for bad quality audit reports. However, the new rule tries to keep the legal liability unchanged from the audit partner's perspective. Form AP is the form used to disclose partner names and from the SEC release number 34-777082 we have the following statements - "Most accounting firms that commented on the issue agreed that Form AP would address some or all of their liability concerns" and "The Board believes that disclosure on Form AP appropriately addresses concerns raised by commenters about liability." Thus, the legal consequences of transparency should be minimal and should not affect our qualitative results.

${ }^{19}$ We will describe the actions taken by these players further in this section.

${ }^{20}$ This assumption is for simplicity and does not change our results qualitatively.
} 
period is revealed to all players. One engagement partner audits the issuer and the partner who does not work with the issuer is engaged in another project that we name Project 2. We assume that Project 2 is one in which a partner of any type (partner types will become clear shortly) plays the same action and therefore the reputation of the partner is unaffected by its outcome. ${ }^{21}$ As is clear, we are primarily interested in the issuer's project and we call it the good state of the world if the cash flow drawn by nature in that period is $G$, else it is the bad state of the world.

The issuer must hire the audit firm in every period. ${ }^{22}$ After the issuer hires the audit firm in Period 1, an unbiased coin is tossed to decide which engagement partner works with the issuer in that period and which partner works on Project 2. The issuer, engagement partners and the managing partner observe the realization of this coin toss. Under the non-disclosure regime, the investor does not know the identity of the partner chosen to issue the audit report for the issuer. Under the disclosure regime, the identity of the partner is observed by the investor as well. Partner rotation and monitoring occur as follows. In Period 2, the partner continues to be with the issuer with probability $\gamma$. With probability $1-\gamma$, the other partner is assigned to the issuer. The investor does not observe the switch in partners in the non-disclosure regime (but does so in the disclosure regime). However, the parameter $\gamma$ is common knowledge to all players.

Each period, the partner assigned to the issuer gets a signal $s \in\{g, b\}$ about the true cash flow in that period. The conditional distribution of signals is as follows. The audit partner observes the signal $g$ whenever the true cash flow is $G$. However, if the true cash flow is $B$ the audit partner observes $g$ with probability $\varepsilon$ and $b$ with probability $1-\varepsilon$. The partner informs the issuer of his signal truthfully. We assume that he cannot misinform the issuer. This is to be interpreted as a file documenting the partner's 'assessment' of the issuer which the partner has to show to the issuer. The audit partner has to announce a signal to all players, in particular to the investor. The investor wants to invest in the issuer only if the state is $G$. He updates his beliefs about the true state being $G$ after observing the signal announced by the partner.

A conflict between the issuer and the auditor occurs whenever the audit partner gets the signal $b$ since, if announced, this could indicate to the investor that the true state is bad, resulting in zero investment by the investor that period. This hurts the payoff of the issuer (payoffs will be described formally later). If there is a conflict, the issuer can commit to a one period $\operatorname{cost}^{23}(\in[0, \infty))$ which he would impose on the partner if the partner chooses to announce $b$ instead of $g$. Putting pressure on the partner is costly for the issuer as well. We assume that the cost of putting pressure level $B$ is $B^{24}$ i.e. the utility from putting pressure $B$ is $-B$.

If the partner gets the signal $b$, he may be pressured into announcing $g$ by the issuer who fears losing that

\footnotetext{
${ }^{21}$ This assumption simplifies our analysis and allows us to focus on the issuer's project.

${ }^{22}$ This may be required by law as observed in the USA.

${ }^{23}$ Alternatively, a transfer. This cost can be interpreted as anything from making life hard for the partner to getting him fired or not offering him a job in the future.

${ }^{24}$ This could be interpreted as an expected loss in the future if this action was discovered, or in the case of a transfer this is simply the amount the issuer has to transfer to get a favorable assessment
} 
period's investment from the investor. If there is a conflict at time $t$, then the partner has two action choices. He can either bow to the pressure and acquiesce (A) (by choosing to announce signal $g$ instead of $b$ to avoid the cost $B$ ) to the issuer or not acquiesce (NA) (announce true signal $b$ ). We focus our attention on the conflict case only and therefore for the 'good' signal, we assume that the partner reports the signal $g$ whenever he gets $g .{ }^{25}$ Thus, if there is no conflict at $t$, then the partner's action set is simply $\{N A\}$ and if there is a conflict at time $t$, the partner's action set is $\{A, N A\}$.

The partners can be one of two types: Rigid $(R)$ or Flexible $(F)$ (we define types following Dye et al. (1990)). At time zero, nature picks the type of the two partners independently from a distribution $\Gamma$ where the probability of being rigid is $p_{h}$. An $R$ type partner is behavioral and never acquiesces. An $F$ type partner is strategic and decides optimally whether to acquiesce or not. A partner's type is his private information. For simplicity, we assume that the issuer knows that partner's type but the investor does not. ${ }^{26}$ Naturally, we will describe all strategies for the flexible type partner only since the other type is behavioral.

The partner assigned to the issuer in period 2 learns if the previous partner had acquiesced or not. We interpret this as the new partner being able to figure out if the audit evidence supports the audit opinion issued by reading the papers filed by the old partner. He then decides whether to report his predecessor to the managing partner with a message correct or incorrect $\{C, N C\}$ (the former indicates that the audit evidence supports the audit opinion and the latter says it does not). While reporting $C$ is costless, there is a fixed cost $c$ for reporting a partner's action to be $N C$. This is to be interpreted as a personal cost of confrontation or conflict with a fellow partner. Reuben and Stephenson (2013) show that individuals who report against fellow group members are often shunned later. Alternatively, this cost can be interpreted as the cost of having to go through the entire investigation procedure after making the accusation. In our model, we assume $c>0$. We relax this in the internet appendix and show how having a zero cost of reporting changes the results.

It is assumed that if a partner reports that the other partner played $A$ in the previous period, then his accusation will be investigated and the investigation will always reveal the truth. It is also assumed that if the partner reports $C$, then there will be no further investigation from the leadership of the firm (we could alternatively assume a lower probability of investigation). Both types of partners are strategic when it comes to making the decision of incurring $c$ and reporting on the other partner. ${ }^{27}$

The consequences of monitoring are as follows. Following a report $N C$, there is an investigation which

\footnotetext{
${ }^{25}$ One may wonder if this is reasonable. In particular, could the partner announce $b$ when his true signal is $g$ ? We do not allow for this possibility for the following reasons. One, the issuer may be able to sue the auditor for misreporting if the auditor's signal is $g$ and he chooses to disclose $b$. Remember, the auditor has no supportive evidence for the opinion as the signal he received does not match the signal he discloses. Two, on a similar note, the client can report the partner to the managing partner and this can initiate an investigation on the partner who misreports. A similar assumption has been made by others including McLennan and Park (2016).

${ }^{26}$ In practice, the issuer's manager has a lot more information about the auditor than the investor. This is because the audit process requires frequent interactions between the management and the auditor.

${ }^{27}$ We could alternatively assume that the rigid type is behavioral about reporting too and always reports all discrepancies. This would not change our qualitative results.
} 
reveals the true signal obtained by the previous partner to the managing partner. The managing partner is behavioral and fires (action $f$ ) a partner if and only if he finds out that the partner had not reported his true signal. The fired partner is replaced by another partner from the distribution $\Gamma$ immediately (at no cost). If a partner reports against the other partner, but investigations reveal this to be untrue, then the reporting partner is fired. The investor observes if a partner has been fired. ${ }^{28}$ If the reporting partner reports $C$, the managing partner always takes the action of not firing (action $n f$ ).

The reputation of the audit firm at time $t$ indicates the beliefs held by the investor about the probability that the partner assigned to the issuer in period $t$ is of type $R$. The reputation at time $t$ is given by $R_{t}$. In period one, this is the reputation at the beginning of the period, that is, $p_{h}$. In period 2, this is the reputation of the audit firm after the managing partner has made his firing decision. Let $R_{2}^{\prime}$ indicate the probability that the partner engaged in project 2 is of $R$ type.

The investor updates his beliefs about the true state being $G$ and then makes his investment decision. We assume that the investor invests the amount $I \times \operatorname{Pr}\left(G \mid s, R_{t}\right)^{29}$ in the issuer's firm where $\operatorname{Pr}\left(G \mid s, R_{t}\right)$ is the posterior probability of the true state being $G$ given that engagement partner $i$ announced the signal $s$ and the reputation of the audit firm is $R_{t}$. $I$ is a fixed positive constant indicating the size of the investment. The investment by the investor in period $t$ is denoted by $i(t)$.

We introduce errors as a way to refine the set of equilibria and to deal with belief revision following zero probability events ${ }^{30}$ in a consistent manner. All partners make an error in announcing the signal with probability $v$. This means that if the partner wanted to announce a signal, he announces it with probability $1-v$ and announces the other signal with probability $v$. We will present all results assuming $v \rightarrow 0$. Thus, our equilibrium concept will be extensive form trembling hand perfect equilibrium. The following assumption also deals with possible off equilibrium events. We assume that there is a small probability that the partner in period one gets fired regardless of his signal or state realization. This is to deal with beliefs following a history where the signal was $g$, the state realized was $G$, but the partner was fired.

\subsection{Timeline}

At the beginning of the first period, nature draws the type of the two engagement partners from the distribution $\Gamma$ and randomly assigns one of the two partners to the issuer. Then, nature picks the true state of the world (true cash flow for issuer) for period 1 and the engagement partner receives a signal $(s \in\{g, b\})$. The engagement partner

\footnotetext{
${ }^{28}$ This assumption is for simplicity. We can obtain the same qualitative results without this assumption, albeit in a longer (but finite) time horizon.

${ }^{29}$ Any investment function, increasing in the investor's expectation about the probability of the $G$ state, will qualitatively produce similar results.

${ }^{30}$ For example - what are the beliefs if the signal announced is $b$ but the state is revealed to be $G$ at the end of period 1 ? Unless partners can make mistakes, this cannot happen as the engagement partner has to receive the signal $g$ in state $G$ and in this case the partner's action set is singleton $\{N A\}$.
} 
communicates the signal to the issuer truthfully. If there is a conflict, the issuer commits to how much pressure he would put on the partner in case the partner plays $N A$ and communicates this to the partner. The engagement partner chooses to acquiesce or not and publicly announces a signal. If there is no conflict, the engagement partner announces his true signal $(g) .{ }^{31}$ After observing the signal, the investor makes the investment decision. All players receive their first period payoffs. At the end of the first period, the true cash flow for the first period is observed by all players. ${ }^{32}$

At the beginning of the second period, nature picks the partner to be assigned to the issuer in period 2 (probability of picking the same partner is $\gamma$ ). The partner assigned to the issuer learns about the signals and actions of the previous partner. The new partner decides whether to report against the previous partner or not. The managing partner makes the firing decision. If a partner is fired, he is replaced by a partner drawn from the distribution $\Gamma$ immediately. The investor observes whether a partner has been fired or not but may not observe the identity of the fired partner. ${ }^{33}$ Next, nature draws the true cash flow for period 2 for the issuer and sends a signal to the assigned partner $(s \in\{g, b\})$. The engagement partner communicates the signal to the issuer truthfully. If there is a conflict, the issuer commits to how much pressure he would put on the partner in case the partner plays $N A$ and communicates this to the partner. The engagement partner chooses to acquiesce or not and publicly announces a signal. If there is no conflict, the engagement partner announces the true signal $(g)$. After observing the signal, the investor makes the investment decision. All players get their second period payoffs. The true cash flow for the second period is observed by all players. The game ends.

\subsection{Payoffs and Strategies}

In each period, the payoffs of players depend on the reputation of the two partners, the sharing rule, the action taken by the engagement partner and the cost imposed by the issuer in case the partner does not acquiesce in a conflict. Let $I_{a}^{i}$ be an indicator function which takes the value 1 when partner $i$ is assigned to the issuer. Let $I_{c}$ be an indicator function which equals 1 when there is conflict. If a partner is fired in the first period, his payoff in the second period is given by the outside option $v_{f}(\leq 0)$. Essentially, the total audit firm's fees in any period is a linear combination of the reputations of its two partners. The engagement partners get a share of this and the managing partner of the audit firm is the residual claimant. The issuer gets whatever the investor invests. Since we assume the investor to be behavioral, we do not model his payoffs.

Suppose the issuer commits to impose a $\operatorname{cost} B$ on the partner if he plays $N A$ in case of a conflict at period $t$. Then the period/stage payoffs for the players in the game at time $t$ is given by the following functions of the

\footnotetext{
${ }^{31}$ If there is no conflict the signal has to be $g$.

${ }^{32} \mathrm{We}$ discuss this further in section 7.

${ }^{33}$ The investor observes the identity in the disclosure regime and does not observe in the non-disclosure regime.
} 
action taken by the engagement partner:

$$
\begin{aligned}
\text { Managing Partner }(A, N A)= & \left(1-\alpha_{1}-\beta_{1}\right)\left(W R_{t}\right)+\left(1-\alpha_{2}-\beta_{2}\right)\left(X R_{t}^{\prime}\right) \\
\operatorname{Partner}^{i}(N A)= & I_{a}^{i}\left[I_{c}\left(\alpha_{1}\left(W R_{t}\right)+\alpha_{2}\left(X R_{t}^{\prime}\right)-B\right)+\left(1-I_{c}\right)\left(\alpha_{1}\left(W R_{t}\right)+\alpha_{2}\left(X R_{t}^{\prime}\right)\right)\right]+ \\
& \left(1-I_{a}^{i}\right)\left[\beta_{1}\left(W R_{t}\right)+\beta_{2}\left(X R_{t}^{\prime}\right)\right] \\
\operatorname{Partner}^{i}(A)= & I_{a}^{i}\left[\alpha_{1}\left(W R_{t}\right)+\alpha_{2}\left(X R_{t}^{\prime}\right)\right]+\left(1-I_{a}^{i}\right)\left[\beta_{1}\left(W R_{t}\right)+\beta_{2}\left(X R_{t}^{\prime}\right)\right] \\
\operatorname{Issuer}(N A)= & I_{c} \cdot\left(\operatorname{I} \cdot \operatorname{Pr}\left(G \mid b, R_{t}\right)-B\right)+\left(1-I_{c}\right) \operatorname{I.Pr}\left(G \mid g, R_{t}\right) \\
\operatorname{Issuer}(A)= & I . P r\left(G \mid g, R_{t}\right)
\end{aligned}
$$

$\alpha_{1}, \alpha_{2}, \beta_{1}, \beta_{2} \in(0,1)$ are the shares of the engagement partners. $\alpha_{1}$ and $\alpha_{2}$ are the shares of the engagement partner assigned to the issuer, where $\alpha_{1}$ is his share of the audit fee received from the issuer and $\alpha_{2}$ is his share of the revenue from Project 2. Similarly, $\beta_{1}$ and $\beta_{2}$ are the other partner's share of the audit fee from the issuer and Project 2 revenue respectively. Audit fees for the issuer and Project 2 are $W R_{t}$ and $X R_{t}^{\prime}$ respectively. $X$ and $W$ are positive scalars and $R_{t}$ and $R_{t}^{\prime}$ are the probabilities that the partner assigned to the issuer and Project 2 is of the rigid type respectively. Thus, the audit fee structure is exogenous to the model (even though the actual fees does depend upon the endogenously determined reputation) and is directly proportional to the reputation of the audit partner. We discuss this assumption further in section 7.

A strategy for an engagement partner is a set of history contingent actions, where the action set in period 1 is $\{A, N A\}$ in case of conflict and $\{N A\}$ if there is no conflict. The action set in period 2 is $\{A, N A\} *\{C, N C\}$ in case of conflict in period 2 and $\{N A\} *\{C, N C\}$ in case of no conflict. ${ }^{34}$ The issuer's strategy is a pair of history contingent actions $\left(B_{1}, B_{2}\right)$, which specifies the amount of pressure he puts on an assigned partner in case of a conflict in period 1 and 2 respectively.

\section{Analysis}

In this section, we show that when the cost of monitoring is positive, under some conditions we have monitoring equilibria under the non-disclosure regime but not under the disclosure regime. No monitoring may lead to lower audit quality under the disclosure regime. By lower audit quality, we mean that there is a higher probability that the flexible partner succumbs to issuer's pressure and plays $A$ in period 1 . In the internet appendix, we consider the case of zero cost of reporting. We show that in this case, the disclosure regime always outperforms the nondisclosure regime. ${ }^{35}$ This is because when the cost of reporting is zero, monitoring always occurs in equilibrium

\footnotetext{
${ }^{34}$ Notice that action in period 1 is a function of reputation $R_{1}$, the pressure from the manager $B_{1}$, and the partner's belief about the second period reporting action $r \in\{C, N C\}$ of the other partner.

${ }^{35}$ In terms of Audit quality.
} 
in both regimes. Thus, the cost of reporting and changing monitoring incentives ${ }^{36}$ are key to understanding the impact of the new rule on audit quality.

We start by making clear that the second period flexible engagement partner will always play A and therefore the only action of interest is the first period strategy of the flexible engagement partner and the reporting behavior of the successor partner.

Claim 1. At $t=2$, in case of a conflict, $B_{2}=0$ and if the $F$ type partner is assigned to the issuer then he plays A irrespective of the disclosure requirement.

Proof. As the game ends at $t=2$, an $F$ type partner has no reputation concern in this period, and is indifferent between playing $A$ and $N A$ in period 2 if the pressure imposed is zero. If $B_{2}>0$, the partner strictly prefers the action $A$. Therefore, the issuer can induce the partner to play $A$ at no cost. Thus, in any equilibrium we must have that the partner plays $A$ when he is indifferent (any other play would not be part of equilibrium strategy as the issuer can always impose a small positive cost). This implies that, in equilibrium, the issuer will choose $B_{2}=0$ and the partner will play $A$.

Claim 1 shows that in the second period, which is also the last period of the game, the partner acquiesces to the issuer in any equilibrium. Thus, the only actions of interest are the first period action choice by the flexible partner and the reporting choice of the successor partner in period two.

Next, we look for conditions under which the disclosure regime produces lower quality audit reports as compared to the non-disclosure regime. We will show our desired result in three steps. First, we find conditions under which the only equilibrium in the disclosure regime is one in which the successor partner never reports the predecessor partner. Second, we find conditions under which there exists a reporting equilibrium in the nondisclosure regime. Finally, using the first two results, we find conditions under which the audit quality in the reporting equilibrium in the non-disclosure regime is higher than the audit quality in the disclosure regime.

\subsection{Disclosure Regime}

This subsection shows that if the cost of reporting is high enough, there is a unique equilibrium in the disclosure regime. Furthermore, there is no monitoring in this equilibrium i.e. the successor partner never reports the predecessor partner and so the latter is never fired. We start with a lemma demonstrating no reporting in the disclosure regime.

Lemma 1. If $c>\underline{c}=\frac{\alpha_{2} X p_{h}(1-\varepsilon)\left(1-p_{h}\right)}{p_{h} \varepsilon+\left(1-p_{h}\right)}$, then there is no equilibrium where the successor partner reports with positive probability in the disclosure regime.

\footnotetext{
${ }^{36}$ As we go from a non-disclosure regime to disclosure regime.
} 
Proof. We prove this by contradiction. Suppose there is an equilibrium where the successor partner reports with positive probability $\mu$. Consider an equilibrium in which the flexible partner's strategy in period 1 is such that, in case of conflict, he plays A with probability $x$. The successor partner reports a discrepancy with probability $\mu$, where $\mu$ is assumed to be strictly greater than zero.

Consider the reporting decision in period 2:

$$
\begin{aligned}
& \text { Payoff from reporting }=\alpha_{1} W p_{h}+\alpha_{2} X p_{h}-c \\
& \text { Payoff from not reporting }=\alpha_{1} W p_{h}+\alpha_{2} X p^{\prime}
\end{aligned}
$$

where $p^{\prime}$ is reputation of the other partner in the history $(g, B, n f)$ (signal announced was $g$, state revealed at end of period 1 was $B$, and no firing was observed.). Bayesian updating gives us that:

$$
p^{\prime}=\frac{p_{h} \varepsilon}{p_{h} \varepsilon+\left(1-p_{h}\right)(\varepsilon+(1-\varepsilon) x(1-\mu))}
$$

Case $1-\mu=1$ (successor partner reports with probability 1). In this case, the above condition implies that $p^{\prime}=p_{h}$. However in this case, payoff from not reporting $\left(\alpha_{1} W p_{h}+\alpha_{2} X p_{h}\right)$ exceeds the payoff from reporting $\left(\alpha_{1} W p_{h}+\alpha_{2} X p_{h}-c\right)$, which implies that the successor partner should never report in equilibrium i.e. $\mu$ should be zero. Contradiction.

Case $2-\mu \in(0,1)$ (successor partner mixes between reporting and not reporting). The required indifference condition for mixing implies:

$$
c=\alpha_{2} X p_{h}\left(1-\frac{\varepsilon}{p_{h} \varepsilon+\left(1-p_{h}\right)(\varepsilon+(1-\varepsilon) x(1-\mu))}\right)
$$

However, the lemma assumes that $c>\underline{c}$ and it is clear that $\underline{c}>\alpha_{2} X p_{h}\left(1-\frac{\varepsilon}{p_{h} \varepsilon+\left(1-p_{h}\right)(\varepsilon+(1-\varepsilon) x(1-\mu))}\right)$. Therefore the indifference condition cannot hold.

Case 1 and case 2 imply that we cannot have an equilibrium where the successor partner reports with positive probability in the disclosure regime.

The intuition for the above result is as follows. First, since partner names are disclosed, when there is partner rotation and a new audit partner is assigned to the issuer in period 2, the new partner cannot change beliefs about his own reputation. The investor knows that the partner assigned to the issuer in period 2 has a reputation of $p_{h}$. Second, though the engagement partner can improve the reputation of the other partner by reporting discrepancies ${ }^{37}$, if the cost of reporting is high enough, the payoff gain from the increased reputation

\footnotetext{
${ }^{37}$ Then, the investor would observe a firing and would figure out that the other partner is a new partner drawn from the pool and therefore has reputation $p_{h}$.
} 
of the other partner does not compensate for the cost of reporting. Note that the payoff gain from reporting the other partner is actually reducing in $\mu$. This is because if the investor believes that the successor partner will report the predecessor partner for playing $A$ with high probability, the incentives to deviate and not report the previous partner increases for the successor partner. The idea is that if the investor observes no firing, then he is more likely to believe that this is due to the first partner getting a wrong signal (else the successor partner would have likely reported him and there would be a firing). However, both type partners can get the wrong signal with equal probability so the reputation of the predecessor partner doesn't fall by much if the there is no firing and the investor believes that the successor partner will report with high probability. Next, we outline the unique equilibrium in the disclosure regime.

Proposition 1. If $c>\underline{c}=\frac{\alpha_{2} X p_{h}(1-\varepsilon)\left(1-p_{h}\right)}{p_{h} \varepsilon+\left(1-p_{h}\right)}, \exists$ an $I_{D}$ such that the unique equilibrium in the disclosure regime has the following features:

a) The successor partner never reports the predecessor partner

b) If $I \geq I_{D}$, then the flexible partner always plays $A$ in period 1 in case of a conflict.

c) If $I<I_{D}$, there exists a unique $x(I)$ such that, in case of a conflict, the flexible partner plays $A$ with probability $x(I)$ in period 1 .

Proof. Lemma 1 already demonstrates the first claim. Consider the following general strategy for the flexible partner in period 1: in case of a conflict, the flexible partner plays $A$ with probability $x$.

The first thing to note is that $x$ cannot take the value zero in equilibrium. This is because, in this case, both the flexible and the rigid partner are believed to play the same strategy in period 1 and thus there is no updating of belief by the investor for any observed history. In particular, the flexible partner cannot lose reputation by playing $A$ and since there is no reporting, the flexible partner is not fired for playing $A$. Thus, the flexible partner has incentives to deviate and play $A$ in period 1 in case of a conflict, thereby avoiding the cost imposed by the issuer while facing no loss of reputation.

Whether $x$ takes a value in $(0,1)$ or 1 depends upon the maximum pressure the issuer-manager is willing to impose on the partner. This is the difference in payoff of the issuer when the engagement partner plays A in period 1 as compared to when the engagement partner plays NA in period 1. Thus, we have the following expression for maximum pressure:

$$
\max _{B}=\frac{p I}{p+(1-p)\left(p_{h} \varepsilon+\left(1-p_{h}\right)(\varepsilon+(1-\varepsilon) x)\right)}
$$

For any $x \in(0,1)$, we must have $B=\max _{B}$, else the issuer manager can induce a flexible partner to play $A$ by increasing the pressure by a very small amount. If $x=1$, we must have $B \leq \max _{B}$.

If $x \in(0,1)$, the flexible partner must be indifferent between playing $A$ and playing $N A$. Thus, we must 
have:

$$
\begin{aligned}
& \text { Payoff from } A=\text { Payoff from } N A \\
& \Leftrightarrow \alpha_{1} W p_{h}+\alpha_{2} X p_{h}+\delta\left[\gamma\left(\alpha_{1} W p^{\prime}+\alpha_{2} X p_{h}\right)+(1-\gamma)\left(\beta_{1} W p_{h}+\beta_{2} X p^{\prime}\right)\right]=\alpha_{1} W p_{h}+\alpha_{2} X p_{h}-B+ \\
& \delta\left[\gamma\left(\alpha_{1} W \frac{p_{h}}{p_{h}+\left(1-p_{h}\right)(1-x)}+\alpha_{2} X p_{h}\right)+(1-\gamma)\left(\beta_{1} W p_{h}+\beta_{2} X \frac{p_{h}}{p_{h}+\left(1-p_{h}\right)(1-x)}\right)\right] \\
& \Leftrightarrow B=\delta\left[\gamma \alpha_{1} W+(1-\gamma) \beta_{2} X\right]\left[\frac{p_{h}}{p_{h}+\left(1-p_{h}\right)(1-x)}-p^{\prime}\right] \\
& \Leftrightarrow B=\delta\left[\gamma \alpha_{1} W+(1-\gamma) \beta_{2} X\right]\left[\frac{p_{h}}{p_{h}+\left(1-p_{h}\right)(1-x)}-\frac{p_{h} \varepsilon}{p_{h} \varepsilon+\left(1-p_{h}\right)(\varepsilon+(1-\varepsilon) x)}\right]
\end{aligned}
$$

Now, for $x \in(0,1)$ to be optimal, it must be the case that the issuer-manager cannot put a little more pressure to make playing $A$ strictly better than playing $N A$. Thus, we must have $B=\max _{B}$. This implies

$$
\begin{aligned}
& \delta\left[\gamma \alpha_{1} W+(1-\gamma) \beta_{2} X\right]\left[\frac{p_{h}}{p_{h}+\left(1-p_{h}\right)(1-x)}-\frac{p_{h} \varepsilon}{p_{h} \varepsilon+\left(1-p_{h}\right)(\varepsilon+(1-\varepsilon) x)}\right]=\frac{p I}{p+(1-p)\left(p_{h} \varepsilon+\left(1-p_{h}\right)(\varepsilon+(1-\varepsilon) x)\right)} \\
& I=\frac{\left[p+(1-p)\left(p_{h} \varepsilon+\left(1-p_{h}\right)(\varepsilon+(1-\varepsilon) x)\right)\right] \delta\left[\gamma \alpha_{1} W+(1-\gamma) \beta_{2} X\right]}{p}\left[\frac{p_{h}}{p_{h}+\left(1-p_{h}\right)(1-x)}-\frac{p_{h} \varepsilon}{p_{h} \varepsilon+\left(1-p_{h}\right)(\varepsilon+(1-\varepsilon) x)}\right]
\end{aligned}
$$

Thus, we get that the equilibrium $x$ is an increasing function of $I$. Given any $I<I_{D}$ where $I_{D}=\frac{p+(1-p)\left(p_{h} \varepsilon+1-p_{h}\right)}{p} \delta\left(\gamma \alpha_{1} W+\right.$ $\left.(1-\gamma) \beta_{2} X\right) \frac{1-p_{h}}{p_{h} \varepsilon+\left(1-p_{h}\right)}$, there exists a unique $x(I) \in(0,1)$ such that $B=\max _{B}$ and payoff from A equals payoff from NA. If $I \geq I_{D}$, then optimal $x$ is 1 .

Thus, if the investment amount is very large, the issuer manager loses too much if the audit partner reports the unfavorable signal. Thus, the issuer manager has incentives to put a lot of pressure on the partner which guarantees that the flexible partner succumbs to the pressure and plays $A$. Next, we find conditions under which there is a reporting equilibrium in the non-disclosure regime.

\subsection{Non-Disclosure Regime}

In the previous subsection, we saw that under some conditions, the unique equilibrium in the disclosure regime is one in which there is no monitoring. We would like to show that though the disclosure regime has more 'transparency', this may not necessarily be good. To this end, in this subsection, we study the non-disclosure regime and we look for equilibria where the successor partner always reports the predecessor partner in case of a discrepancy between the audit signal and the audit announcement. Using this result, in the next subsection we will identify conditions under which the non-disclosure regime produces higher audit quality reports as compared to the disclosure regime. The following proposition identifies an equilibrium with reporting in the non-disclosure regime.

Proposition 2. If $c<\bar{c}=\frac{\alpha_{1} W p_{h}\left(1-p_{h}\right)(1-\varepsilon) \gamma}{\varepsilon p_{h}+\left(1-p_{h}\right)(\varepsilon+(1-\varepsilon) \gamma)}$, then $\exists$ an $I_{N D}, \underline{I}$ such that there is an equilibrium in the nondisclosure regime which has the following features:

a) The successor partner always reports the predecessor partner

b) If $I \geq I_{N D}$, then the flexible partner always plays $A$ in period 1 in case of a conflict. 
c) If $\underline{I}<I<I_{N D}$, there exists a unique $x(I)$ such that, in case of a conflict, the flexible partner plays A with probability $x(I)$ in period 1 .

Proof. Consider the reporting decision in period 2 now:

$$
\begin{aligned}
& \text { Payoff from reporting }=\alpha_{1} W p_{h}+\alpha_{2} X p_{h}-c \\
& \text { Payoff from not reporting }=\alpha_{1} W R(x)+\alpha_{2} X R^{\prime}(x)
\end{aligned}
$$

where $R(x)$ is the reputation of the partner assigned to the client in period 2 and $R^{\prime}(x)$ is reputation of other partner following history $(g, B, n f)$ and reporting is an equilibrium strategy. Therefore:

$$
\begin{aligned}
& R(x)=\frac{p_{h} \varepsilon}{p_{h} \varepsilon+\left(1-p_{h}\right)(\varepsilon+(1-\varepsilon) x \gamma)} \\
& R^{\prime}(x)=p_{h}
\end{aligned}
$$

Since we are looking for an equilibrium where reporting is optimal, we must have:

$$
\begin{aligned}
& \text { Payoff from not reporting }<\text { Payoff from reporting } \\
& \Leftrightarrow \alpha_{1} W R(x)+\alpha_{2} X R^{\prime}(x)<\alpha_{1} W p_{h}+\alpha_{2} X p_{h}-c \\
& \Leftrightarrow c \leq \frac{\alpha_{1} W p_{h}\left(1-p_{h}\right)(1-\varepsilon) x \gamma}{\varepsilon p_{h}+\left(1-p_{h}\right)(\varepsilon+(1-\varepsilon) x \gamma)}
\end{aligned}
$$

The right hand side (RHS) expression is increasing in $x$. Define $c(x)=\frac{\alpha_{1} W p_{h}\left(1-p_{h}\right)(1-\varepsilon) x \gamma}{\varepsilon p_{h}+\left(1-p_{h}\right)(\varepsilon+(1-\varepsilon) x \gamma)}$. Then $\bar{c}$ is the highest value of RHS (c(1)). By assumption in the proposition $c<\bar{c}$. Let $\underline{x}$ be such that $c(\underline{x})=c$. Then, for all $x \in[\underline{x}, 1], c(x) \geq c$.

Consider period 1 equilibrium behavior now. For all equilibria in which the flexible partner plays $A$ with probability $x$ when there is a conflict, if $x \in(0,1)$, we must have:

$$
\begin{aligned}
& \text { Payoff from } A=\text { Payoff from } N A \\
& \Leftrightarrow \alpha_{1} W p_{h}+\alpha_{2} X p_{h}+\delta\left[\gamma\left(\alpha_{1} W R(x)+\alpha_{2} X R^{\prime}(x)\right)+(1-\gamma)\left(v_{f}\right)\right]=\alpha_{1} W p_{h}+\alpha_{2} X p_{h}-B+ \\
& \delta\left[\gamma \left(\alpha_{1} W\left(\gamma \frac{p_{h}}{p_{h}+\left(1-p_{h}\right)(1-x)}+(1-\gamma) p_{h}\right)+\alpha_{2} X\left((1-\gamma) \frac{p_{h}}{p_{h}+\left(1-p_{h}\right)(1-x)}+\gamma p_{h}\right)+\right.\right. \\
& \left.(1-\gamma)\left(\beta_{1} W\left(\gamma \frac{p_{h}}{p_{h}+\left(1-p_{h}\right)(1-x)}+(1-\gamma) p_{h}\right)+\beta_{2} X\left((1-\gamma) \frac{p_{h}}{p_{h}+\left(1-p_{h}\right)(1-x)}+\gamma p_{h}\right)\right)\right] \\
& \Leftrightarrow B=\delta\left[\gamma \alpha_{1} W\left(R_{h}(x)-R(x)\right)+\gamma \alpha_{2} X\left(R_{h}^{\prime}(x)-R^{\prime}(x)\right)+(1-\gamma)\left(\beta_{1} W R_{h}(x)+\beta_{2} X R_{h}^{\prime}(x)-v_{f}\right)\right]
\end{aligned}
$$

where $R_{h}(x)=\gamma \frac{p_{h}}{p_{h}+\left(1-p_{h}\right)(1-x)}+(1-\gamma) p_{h}$ and $R_{h}^{\prime}(x)=(1-\gamma) \frac{p_{h}}{p_{h}+\left(1-p_{h}\right)(1-x)}+\gamma p_{h}$

For any $x \in(0,1)$, we must have $B=\max _{B}$, else the issuer manager can definitely get $A$ behavior from the flexible partner by increasing the pressure by a very small amount. If $x=1$ (A equilibrium), we must have 
$B \leq \max _{B}$. Thus, if $x \in(0,1)$, we must have:

$$
\begin{aligned}
& \delta\left[\gamma \alpha_{1} W\left(R_{h}(x)-R(x)\right)+\gamma \alpha_{2} X\left(R_{h}^{\prime}(x)-R^{\prime}(x)\right)+(1-\gamma)\left(\beta_{1} W R_{h}(x)+\beta_{2} X R_{h}^{\prime}(x)-v_{f}\right)\right]=\frac{p I}{p+(1-p)\left(p_{h} \varepsilon+\left(1-p_{h}\right)(\varepsilon+(1-\varepsilon) x)\right)} \\
& \Leftrightarrow I=\frac{\left[p+(1-p)\left(p_{h} \varepsilon+\left(1-p_{h}\right)(\varepsilon+(1-\varepsilon) x)\right] \delta\left[\gamma \alpha_{1} W\left(R_{h}(x)-R(x)\right)+\gamma \alpha_{2} X\left(R_{h}^{\prime}(x)-R^{\prime}(x)\right)+(1-\gamma)\left(\beta_{1} W R_{h}(x)+\beta_{2} X R_{h}^{\prime}(x)-v_{f}\right)\right]\right.}{p}
\end{aligned}
$$

Thus, we get once again that the equilibrium $x$ is an increasing function of $I$. Choose $\underline{I}$ to be such that the above equation is solved by $\underline{x}$. Now, given any $\underline{I}<I<I_{N D}=\frac{p+(1-p)\left(p_{h} \varepsilon+\left(1-p_{h}\right)\right)}{p} \delta\left[\gamma \alpha_{1} W\left(R_{h}(1)-R(1)\right)+\right.$ $\left.\gamma \alpha_{2} X\left(R_{h}^{\prime}(1)-R^{\prime}(1)\right)+(1-\gamma)\left(\beta_{1} W R_{h}(1)+\beta_{2} X R_{h}^{\prime}(1)-v_{f}\right)\right]$, we have that reporting is optimal and there exists a unique $x(I) \in(0,1)$ such that $B=\max _{B}$ and payoff from A equals payoff from NA. If $I \geq I_{N D}$, then optimal $x$ is 1 .

Next, we find conditions under which the non-disclosure regime produces higher audit quality (probability of flexible partner playing A in period 1 is lower under non-disclosure regime) as compared to the Disclosure regime.

\subsection{Non-Disclosure $>$ Disclosure}

Theorem 1. There exist $c_{1}, c_{2}, I_{1}, I_{2}, \underline{v}$ and $\bar{\alpha}$ such that if the following hold:

$$
\begin{aligned}
& \text { 1. } c \in\left(c_{1}, c_{2}\right) \\
& \text { 2. } I \in\left(I_{1}, I_{2}\right) \\
& \text { 3. } v_{f}<\underline{v} \text { and } \alpha_{2}<\bar{\alpha}
\end{aligned}
$$

then, in any equilibrium, there is no monitoring under the disclosure regime but a monitoring equilibrium exists under the non-disclosure regime. Moreover, the probability of the flexible partner playing $A$ under the nondisclosure regime is strictly lower than that under the disclosure regime.

Proof. We will prove the theorem using a couple of lemmas:

Lemma 2. $\exists \bar{\alpha}$ such that if $\alpha_{2}<\bar{\alpha}$ then $\underline{c}<\bar{c}$.

Proof. $\underline{c}<\bar{c}$ iff:

$$
\begin{aligned}
& \frac{\alpha_{2} X p_{h}(1-\varepsilon)\left(1-p_{h}\right)}{\varepsilon p_{h}+\left(1-p_{h}\right)}<\frac{\alpha_{1} W \gamma p_{h}(1-\varepsilon)\left(1-p_{h}\right)}{\varepsilon p_{h}+\left(1-p_{h}\right)(\varepsilon+(1-\varepsilon) \gamma)} \\
& \Leftrightarrow \alpha_{2}<\frac{\alpha_{1} W \gamma\left[\varepsilon p_{h}+\left(1-p_{h}\right)\right]}{X\left[\varepsilon p_{h}+\left(1-p_{h}\right)(\varepsilon+(1-\varepsilon) \gamma)\right]}
\end{aligned}
$$

Clearly our lemma statement is true for $\bar{\alpha}=\frac{\alpha_{1} W \gamma\left[\varepsilon p_{h}+\left(1-p_{h}\right)\right]}{X\left[\varepsilon p_{h}+\left(1-p_{h}\right)(\varepsilon+(1-\varepsilon) \gamma)\right]}$ 
Lemma 3. $\exists \underline{v}$ such that if $v_{f}<\underline{v}$ then $I_{D}<I_{N D}$

Proof. $I_{D}<I_{N D}$ iff:

$\frac{\left[p+(1-p)\left(p_{h} \varepsilon+1-p_{h}\right)\right]\left[\delta\left(\gamma \alpha_{1} W+(1-\gamma) \beta_{2} X\right)\right]\left(1-p_{h}\right)}{p\left[p_{h} \varepsilon+\left(1-p_{h}\right)\right]}<\frac{\left[p+(1-p)\left(p_{h} \varepsilon+\left(1-p_{h}\right)\right)\right]\left[\delta\left[\gamma \alpha_{1} W\left(R_{h}(1)-R(1)\right)+\gamma \alpha_{2} X\left(R_{h}^{\prime}(1)-R^{\prime}(1)\right)+(1-\gamma)\left(\beta_{1} W R_{h}(1)+\beta_{2} X R_{h}^{\prime}(1)-v_{f}\right)\right]\right]}{p}$

Now, since $v_{f}$ is a negative number (payoff if fired), clearly there exists a negative number $\underline{v}$ such that RHS dominates LHS if $v_{f}<\underline{v}$.

Now, using $\underline{I}$ from proposition 2 , pick $I_{1}=\max \left\{\underline{I}, I_{D}\right\}$ and $I_{2}=I_{N D}$. Choose $x_{1}$ to be such that the equation 5 is solved by $I_{1}$. Now pick $c_{1}=\max \left\{\underline{c}, c\left(x_{1}\right)\right\}$ and $c_{2}=\bar{c}$.

Let $c \in\left(c_{1}, c_{2}\right), I \in\left(I_{1}, I_{2}\right), v_{f}<\underline{v}$ and $\alpha_{2}<\bar{\alpha}$. Then, it is clear from proposition 1, proposition 2, lemma 2 and lemma 3 that there is an equilibrium with reporting in the non-disclosure regime while the only equilibrium in the disclosure regime is the one without reporting. Furthermore, since $I$ is in the range $\left(I_{1}, I_{2}\right)$, in case of a conflict, the flexible partner acquiesces always to issuer-manager in period 1 in the disclosure regime while in the non-disclosure regime, the flexible partner issues the correct audit report with positive probability. Therefore, the audit quality is higher in the non-disclosure regime.

The existence of this equilibrium demonstrates conditions under which the probability that the investor gets the correct signal from the engagement partner may be lower in the disclosure regime as compared to the nondisclosure regime. In other words, the quality of audit may actually be lower under the disclosure regime. Let us discuss some of the sufficient conditions for this result so that the reader gets an intuitive idea about the forces at play.

We need the cost of reporting to be neither too high nor too low. It is obvious that if the cost of reporting is too high then the monitor will find it prohibitively costly to report (irrespective of the regime). If the cost of reporting is too low then there may be reporting equilibria under both regimes and in this case it is difficult to say if the audit quality will be higher in one regime or another. In fact, in the internet appendix we show that the disclosure regime performs better than the non-disclosure regime when the cost of reporting is zero, and this is because reporting is always an equilibrium action when the cost of reporting is zero. If monitoring incentives remain the same then the increased reputation building incentives in the disclosure regime ensures higher audit quality in that regime. Thus, the cost of reporting must be bounded below so that we can use lemma 1 to guarantee that there is no reporting equilibria in the disclosure regime. ${ }^{38}$

\footnotetext{
${ }^{38}$ Note that when the cost of reporting is positive, there can not exist a pure strategy reporting equilibrium under the disclosure regime. The basic idea is that if there was a reporting equilibrium then the monitor partner would have incentives to deviate and not report. This is because of the following. The gain from reporting the other partner comes from increases in reputation (for self and the other partner) which leads to higher payoffs. If he reports the previous partner, he pays a cost $c$ and the reputation of the new partner is $p_{h}$ and his own reputation is also $p_{h}$ (since he was just rotated in and the investor can observe that). If he does not report the previous partner, he pays no cost and the investor believes that there was no firing because the previous partner had received the wrong signal and played $N A$ (else he would have been reported since it is a reporting equilibrium). Since the probability of receiving the wrong signal is the same across partner types, the previous partner's reputation is unchanged at $p_{h}$ and of course the monitor partner's reputation is also $p_{h}$ since he was
} 
Aside from the reporting concerns of the monitor partner, for engagement partners to be sufficiently concerned about their own actions to respond to reporting and firing incentives, the bulk of their payoffs must come from their own engagement and not the revenue the firm may earn from project 2. Thus, $\alpha_{2}$ (share of revenue from project 2 that goes to the partner assigned to the issuer) has to be low.

Finally, if the level of investment is too small, the engagement partner may find it optimal to play $A$ with such a low probability that there may not be a reporting equilibrium in the non-disclosure regime as well. ${ }^{39}$ On the other hand, if the level of investment is high, the issuer may always (irrespective of disclosure policy) be able to pressure the engagement partner into playing $A{ }^{40}$ The idea here is that bigger clients hold more sway over audit partners. An interesting point is that when the client can put a lot of pressure (big client - big $I$ ) on the auditor to issue favorable reports, or can put very little pressure (small client - small $I$ ), then the audit quality is unlikely to worsen after the regime change. It's only in the intermediate range that the disclosure regime performs worse than the non-disclosure regime. The implication here is that it is the audit of an intermediate sized client (who does not find it incentive compatible to put too much costly effort into pressuring the audit partner) which is likely to be negatively affected by this rule change. We find an interval of $I$ in which the engagement partner acquiesces with positive probability under the non-disclosure regime but with full probability under the disclosure regime. ${ }^{41}$ This leads to our main result.

\section{Solutions to the monitoring problem}

It is clear from our analysis that disclosure of the engagement partner's identity reduces the monitoring incentives of a successor partner/engagement quality reviewer. It is also evident that an additional external transfer (prize for monitoring) or, analogously, an increased expected external sanction (punishment for not monitoring), can help mitigate this problem. This class of solutions can be implemented only through an increased cost for regulators. In this section, we propose three other solutions. These can be implemented through increased audit fees or through a realignment of incentives within the audit firm.

\subsection{Increase in audit fee}

Carcello and Li (2013) report improved audit quality and increased audit fees in U.K. firms after the partners were required to sign the audit report. The increased audit fee can reflect an increased audit effort to counter

just rotated in and the investor can observe that. Thus, there are no payoff gains from reporting, but there is a positive cost $c$. So the monitor will deviate and not report the predecessor partner. However, this does not rule out mixed strategies on the part of the monitor where he reports with positive probability. We use the lower bound on $c$ to rule out even positive probabilities of reporting under the disclosure regime.

${ }^{39}$ This is because in this case the flexible and the rigid type partners play almost similar strategies, therefore the gain from reporting is low. Since we impose a lower bound on $c$, the cost of reporting may outweigh the gains.

${ }^{40} \mathrm{Gains}$ from $A$ to issuer is high because of high $I$, therefore the maximum pressure the issuer can impose is high.

${ }^{41}$ The payoff from getting fired $\left(v_{f}\right)$ has to be low enough to be able to claim that such an interval exists. 
the increased risk for individual partners. In the context of our model, however, there is another explanation for a rise in audit fees following the implementation of the signature rule. In our model, the audit fee for the partner with the issuer is a linear function of $W R_{t}$. Therefore, a higher $W$ leads to increased incentives for the engagement partner to not acquiesce to the issuer's demands in the case of a conflict. Thus, the increased audit fee may be because the audit firm's management wants to compensate for the reduced incentive to report with an increased incentive to not misbehave. When monitoring comes from the engagement quality reviewer, since the reporting incentives of the EQR are also increasing in audit fees, an increased $W$ can lead to both increased incentives for the engagement partner as well as improved incentives for the EQR.

\subsection{Treating the monitor as the "sink"}

If the compensation contracts in partnerships can collect a penalty from a group of partners and distribute the collected penalty to another group, then the latter is called the "sink." In a natural set up, the risk neutral principal acts as a sink. However, in our model, the managing partner can not act as the sink in equilibrium. This is because only the successor partner or the EQR can observe the action of the engagement partner. Since contracts can only be made on observables, the managing partner cannot impose a penalty on the engagement partner unless the successor partner or the EQR reports against him. To provide incentives for the monitor partner to report, the managing partner must make a transfer to the monitor. From our analysis, it is evident that the minimum transfer the managing partner needs to make in order to ensure monitoring may be higher under the disclosure regime.

\subsection{The modified eat-what-you-kill compensation structure}

Knechel et al. (2013) observe that the Big-4 accounting firms vary in their profit sharing arrangements. At one end of the spectrum there are profit sharing rules close to the lock-step arrangement, where partners are paid according to seniority and their compensation is relatively less sensitive to own performance. On the other end of the spectrum, there are partnerships that follow sharing rules close to the eat-what-you-kill model. In the context of our model, a partner's compensation is linked to the revenues from the issuer and from project 2 through exogenous parameters $\alpha_{1}, \alpha_{2}, \beta_{1}$ and $\beta_{2}$. Clearly, monitoring incentives can be improved by increasing the monitor's share of the revenue from the issuer. In our model an increase in the monitor partner's share of the revenue earned from the issuer can only be achieved by reducing either the share of the engagement partner or by reducing the share of the managing partner. However, we can use this insight in the context of a more general compensation function. Consider the following compensation function for a partner $i$ in a partnership of 
$N$ partners.

$$
\begin{aligned}
& \text { Pay }_{i}=\alpha \times\{\text { Revenue from engagement }\}_{i}+\beta \times\{\text { Revenue from engagements reviewed }\}_{i} \\
& +\theta \times\{\text { Revenue from other engagements }\}+\eta \times\{\text { Revenue from non-audit services }\}
\end{aligned}
$$

A sharing rule relatively less sensitive to own performance will be represented by high values of $\theta$ and $\eta$ while $\alpha$ and $\beta$ will be low. In order to maximize incentives for the monitor partner and the engagement partner, their share of revenue from other engagements and non-audit services should be minimized, while their compensation should be highly sensitive to their performance as an engagement partner and as a reviewer.

\section{Discussion}

In this section we discuss some of our modeling choices.

\subsection{Exogenous Audit fee structure}

It is clear that the problem we highlight, once understood in depth, may be resolved by endogenous compensation contracts. However, the objective of this paper is to focus on the first stage, that is, the comprehensive understanding of an issue that the audit firms and regulators do not seem to be aware of. We have seen no papers or firm statements/concern-letters which talk about the monitoring issue we highlight. Since the relevant parties seem to be unaware of the problem we demonstrate, it is appropriate that we assume that the compensation contract remains unchanged. Cunningham et al. (2018) find no conclusive evidence of an increase in audit fees due to the new rules. In fact, it would not have been unrealistic to assume that the manager of the audit firm reduces compensation incentives after the regime change because she believes that the increased reputation incentives (this consequence was known prior to the introduction of the rule) would make the audit partner produce higher audit quality reports anyway. We show that such a move would have been misguided and would have exacerbated the monitoring issue we highlight even more.

It is important to understand all the channels via which the disclosure rule can impact incentives to produce high quality audit reports. Unless these channels are well understood, it is impossible for the principal to design an optimal contract. Thus, we believe that incorporating endogenous contracts in this model will be a particularly useful after we have a full grasp of all the relevant frictions in this environment. Furthermore, establishing the theoretical channels of incentive change can impact the validity of empirical work as well. For example, if the channel we highlight is not well known in the literature then empirical work on the impact of the rule change may (erroneously) completely attribute any compensation contract change following the implementation of the 
rule to other factors. ${ }^{42}$

\subsection{No other Audit firms}

Our model includes only one audit firm and therefore it does not allow for the possibility that the client can hire a different audit firm. Our intention in this paper is to identify how the change in regulation may impact auditor incentives within any one firm. The result that the rule change will lower audit partner incentive to monitor fellow partners is valid with or without other firms in the market. The presence of other audit firms in the model can only impact the level of monitoring that takes place and the quantitative 'amount' by which reputation and monitoring incentives change when the regime changes. The presence of other firms does not alter the fact that monitoring incentives will go down when the market moves to a disclosure regime. Therefore, they will not change our qualitative results.

\subsection{True State revealed at the end of the period}

In practice, it takes time for incorrect audit reports to be discovered, investigated and then revealed as such to the investors. In our paper, the true state of the world is revealed at the end of each period which allows the investor to discover if an incorrect audit report was issued in that period. While this is not a realistic assumption, it is not crucial for our qualitative result to go through. The key idea in our paper is that the reporting partner will have higher incentives to monitor another partner when reputation is shared (as in a non-disclosure regime) as compared to when partners can build individual reputations. This intuition remains intact even if we assume that audit failures will be discovered only after $n$ periods. ${ }^{43}$

\subsection{Engagement quality reviewer (EQR)}

The analysis in our baseline model explores the incentives of an engagement partner and a monitor partner who may be rotated in to an engagement at the end of the first period. In this subsection, we discuss the more specific case of an Engagement Quality Reviewer (EQR). Engagement quality review is a quality control mechanism used by public accounting firms to monitor the quality of audit engagements. The engagement quality reviewer serves as an evaluator of the performance of the engagement partner and the engagement team. According to the PCAOB Auditing Standard No. 7, the "objective of the engagement quality reviewer is to perform an evaluation of the significant judgements made by the engagement team and the related conclusions reached in forming the overall conclusion on the engagement and in preparing the engagement report, if a report is to be issued, in order to determine whether to provide concurring approval of issuance."

\footnotetext{
${ }^{42}$ One such factor could be the following. It has been argued that the disclosure of audit partner names may induce them to exert more diligence to avoid any perceived increase in legal liability.

${ }^{43}$ We could make the discovery stochastic as well.
} 
Unlike the successor partner, an EQR can detect whether the audit evidence supports the audit opinion before the audit report is issued. Even in this sort of environment, we can show (formal analysis available on request) that the incentives to report an erring partner is higher in the non-disclosure regime. Thus, we continue to obtain a tussle between reputation and monitoring incentives and we can get the equivalent of our main results in this environment as well.

\section{Conclusion}

We highlight a possible pitfall in the quest for transparency by analyzing a new rule affecting the audit markets in the USA. Prior to February 2017, the name of the audit partner was not disclosed in the USA. Our study is motivated by a rule which mandates the disclosure of the name of the lead audit partner for audit reports issued in the United States. We study this change in the information structure and examine its impact on the reputation building and monitoring incentives of players.

Our analysis shows that it is possible that the disclosure regime produces lower quality audit reports due to the trade-off between two opposing incentive effects. While the partner has stronger reputation building incentives under the disclosure regime (which can improve audit quality), the incentives for a monitor partner to raise the flag are actually higher under the non-disclosure regime. The idea is that under the non-disclosure regime, a partner's actions affect the collective reputation of the firm which is shared by other partners in the firm. Hence a monitor partner has incentives to report a partner who misreports to improve the collective (and therefore his own) reputation.

Our model puts structure to the organizational design of audit firms and emphasizes the role of different relational forces that affect the incentives of auditors. This model can be used to study multiple interesting extensions. For example, we could look at the incentives of the leadership of the audit firms to create the right incentives for partners. In our model, we assume that the managing partner imposes sanctions against the engagement partner whenever the latter is found to misreport. A study exploring the strategic behavior of the managing partner and endogenous realignment of compensation structure in this context will provide further insights into this matter. We hope to work on these issues in the future.

\section{References}

Aobdia, D., Lin, C. J., and Petacchi, R. (2015). Capital market consequences of individual audit partners. Accounting Review, 90(6):2143-2176.

Bar-Isaac, H. (2007). Something to prove: reputation in teams. The RAND Journal of Economics, 38(2):495- 
511.

Basu, S. and Ray, K. (2016). Limits to auditor reputational incentives (june 17, 2016).

Beyer, A. and Sridhar, S. S. (2006). Effects of multiple clients on the reliability of audit reports. Journal of Accounting Research, 44(1):29-51.

Blay, A. D., Notbohm, M., Schelleman, C., and Valencia, A. (2014). Audit quality effects of an individual audit engagement partner signature mandate. International Journal of Auditing, 18(3):172-192.

Carcello, J. V. and Li, C. (2013). Costs and benefits of requiring an engagement partner signature: Recent experience in the united kingdom. The Accounting Review, 88(5):1511-1546.

Chen, Z., Morrison, A. D., and Wilhelm, Jr., W. J. (2013). Investment bank reputation and star cultures. Review of Corporate Finance Studies, 2(2):129-153.

Corona, C. and Randhawa, R. (2010). The auditor's slippery slope: An analysis of reputational incentives. Management Science, 56(6):924-937.

Cunningham, L. M., Li, C., Stein, S. E., and Wright, N. S. (2018). What's in a name? initial evidence of us audit partner identification using difference-in-differences analyses. The Accounting Review.

Datar, S. and Alles, M. (1999). The formation and role of reputation and litigation in the auditor-manager relationship. Journal of Accounting, Auditing \& Finance, 14(4):401-428.

DeFond, M. L. and Francis, J. R. (2005). Audit research after sarbanes-oxley. Auditing: A Journal of Practice \& Theory, 24(1):5-30.

Dye, R. A., Balachandran, B. V., and Magee, R. P. (1990). Contingent fees for audit firms. Journal of Accounting Research, 28(2):239-266.

Ely, J. C. and Välimäki, J. (2003). Bad reputation. The Quarterly Journal of Economics, 118(3):785-814.

Fishman, A., Finkelstein, I., Simhon, A., and Yacouel, N. (2014). The economics of collective brands. Working paper.

Holmstrom, B. and Milgrom, P. (1991). Multitask principal-agent analyses: Incentive contracts, asset ownership, and job design. Journal of Law, Economics, \& Organization, Special Issue: Papers from the Conference on the New Science of Organization, (7):24-52.

Hwang, C. and Li, Y. (2018). Analysts' reputational concerns, self-censoring, and the international dispersion effect. Management Science, 64(5):2289-2307. 
John, K., Liu, M., Sunder, J., Lin, K. C., Moore, J., Thevenot, M., and Verdi, R. (2017). Do client firms benefit from mandatory engagement partner signature. Working Paper. Temple University.

Knechel, W. R., Niemi, L., and Zerni, M. (2013). Empirical evidence on the implicit determinants of compensation in big 4 audit partnerships. Journal of Accounting Research, 51(2):349-387.

Knechel, W. R., Vanstraelen, A., and Zerni, M. (2015). Does the identity of engagement partners matter? an analysis of audit partner reporting decisions. Contemporary Accounting Research, 32(4):1443-1478.

Kreps, D. M., Milgrom, P., Roberts, J., and Wilson, R. (1982). Rational cooperation in the finitely repeated prisoners' dilemma. Journal of Economic theory, 27(2):245-252.

Lee, K. and Levine, C. (2016). Audit partner identification and audit quality. Available at SSRN 2777950.

Liu, M. (2017). Economic consequences of implementing the engagement partner: Signature requirement in the uk. International Business Research, 10:9.

McLennan, A. and Park, I.-U. (2016). The market for liars: Reputation and auditor honesty. International Journal of Economic Theory, 12(1):49-66.

Neeman, Z., Oery, A., and Yu, J. (2068). The benefit of collective reputation (december 30, 2016). Discussion paper, Cowles Foundation.

PCAOB (2013). Improving the transparency of audits: Proposed amendments to pcaob auditing standards to provide disclosure in the auditors report of certain participants in the audit. Technical Report PCAOB Release No. 2013-009.

Reuben, E. and Stephenson, M. (2013). Nobody likes a rat: On the willingness to report lies and the consequences thereof. Journal of Economic Behavior \& Organization, 93:384-391.

SEC (2016). Order granting approval of proposed rules to require disclosure of certain audit participants on a new pcaob form and related amendments to auditing standards. Technical Report Release No. 34-77787; File No. PCAOB-2016-01.

Tirole, J. (1996). A theory of collective reputations (with applications to the persistence of corruption and to rm quality). The Review of Economic Studies, 63(1):1-22. 